\title{
Accumulating Wisdom: An Updated Empirical Examination of Class Counsel's Fees in Ontario Class Actions
}

\author{
Benjamin Alarie and Peter Flynn
}

Version Publisher's version

Citation Alarie, Benjamin and Flynn, Peter, Accumulating Wisdom: An Updated

(published version) Empirical Examination of Class Counsel's Fees in Ontario Class Actions (February 2014). (2014) 9(2) Canadian Class Action Review 355-84. http://dx.doi.org/10.2139/ssrn.2363798

Publisher's Statement Reproduced from Canadian Class Action Review: "Alarie, Benjamin and Flynn, Peter, Accumulating Wisdom: An Updated Empirical Examination of Class Counsel's Fees in Ontario Class Actions (February 2014). (2014) 9(2) Canadian Class Action Review 355-84.” By permission of Thomson Reuters Canada Limited.

\section{How to cite TSpace items}

Always cite the published version, so the author(s) will receive recognition through services that track citation counts, e.g. Scopus. If you need to cite the page number of the author manuscript from TSpace because you cannot access the published version, then cite the TSpace version in addition to the published version using the permanent URI (handle) found on the record page.

This article was made openly accessible by $U$ of $T$ Faculty. Please tell us how this access benefits you. Your story matters. 


\title{
ACCUMULATING WISDOM: AN UPDATED EMPIRICAL EXAMINATION OF CLASS COUNSEL'S FEES IN ONTARIO CLASS ACTIONS
}

\author{
Benjamin Alarie and Peter Flynn
}

Abstract: This article presents an empirical analysis of the decisions made by Ontario courts regarding the compensation of class counsel. The authors aim to provide an analytical tool that can be used as a guide for predicting and determining fee approvals in the future. The authors make the analysis more concrete by applying their empirical methodology to five currently ongoing class actions. 


\title{
ACCUMULATING WISDOM: \\ AN UPDATED EMPIRICAL \\ EXAMINATION OF CLASS COUNSEL'S \\ FEES IN ONTARIO CLASS ACTIONS
}

\author{
Benjamin Alarie* and Peter Flynn**
}

\section{A. INTRODUCTION}

In this article, we update and expand upon an earlier study published in The Canadian Class Action Review, "Rethinking the Approval of Class Counsel's Fees in Ontario Class Actions." The earlier analysis included the twenty-nine reported fee approval decisions that had been reached by Ontario courts by 2007 . Over past six years, Ontario judges have expanded on this several fold. Our new analysis encompasses 104 Ontario fee approval decisions. Our focus is on the quantum of approved fees for plaintiff's counsel and its relationship to the time and effort expended by counsel, the nature of the action, and the stage at which the action was resolved.

We illustrate the potential application of this work in heading towards greater reliability and appropriateness in class action fee approvals. Access to justice can be improved through a more consistent and well-informed fee approval process by enabling class counsel to be more confident about the range of fees that are likely to be approved. By anchoring our proposed methodology in existing decisions, and presenting judges and counsel with a range of reasonable and appropriate values, our methodology is informative, provides judges with a reliable checklist of considerations to take into account, and is flexible enough to accommodate differences between cases. By virtue of attention paid to all Ontario fee approval decisions, the system embraces an openness to further development as time goes on and additional cases are decided.

* Associate Dean, first year program, University of Toronto Faculty of Law.

** JD/MA Economics Candidate (2014), University of Toronto Faculty of Law.

l Benjamin Alarie, "Rethinking the Approval of Class Counsel's Fees in Ontario Class Actions" (2007) 4 Can Class Action Rev 15 (Alarie). 
There have been similar initiatives in other areas of law. One prominent recent example is the federal spousal support guidelines, which have improved the consistency and reliability of spousal support awards made by judges pursuant to the Divorce Act. The federal spousal support guidelines, unlike those in respect of child support, are not mandatory. They provide recommendations that are intended to assist judges and parties to arrive at reasonable and just spousal support orders.

Our approach seeks to propose a similar tool for the compensation of class counsel in class proceedings. To this end, in this article we propose one way in which to structure a standardized methodology for judges to approach motions for fee approval in Ontario class actions. If the tool proves to be helpful, we will update it annually to reflect the most recent decisions and provide the most recent version online.

The rest of the article is structured as follows. Section B outlines some of the history and context of class actions in Ontario. Section $C$ outlines the collection of data on 104 reported Ontario cases in which class counsel fees have been approved. Incomplete observations in the statistics are imputed to account for gaps in reporting and are analyzed using a variety of regressive techniques. To illustrate more concretely the utility of the analysis, Section D expands the analysis with an application of projected results for a sample of five currently ongoing class actions. ${ }^{2}$ Section $E$ presents recommendations for the judiciary in future reporting of fee approvals and promotes the principle of consistency in fee approval decisions. The primary goal of this article is to present an updated analysis of the choices regarding class counsel compensation being faced by Ontario courts in class proceedings and to provide a tool that can be used as a guide in determining fee approvals in the future. The analysis should assist judges in deciding whether to approve a given fee agreement under the current provisions of the CPA.

2 Dugal v Manulife Financial Corp, 2013 ONSC 4083, [2013] OJ No 3455 [Manulife]; Parker v Pfizer Canada, 2012 ONSC 3681, [2012] OJ No 5569 [Pfizer]; Schwoob v Bayer Inc, 2013 ONSC 2207, [2013] OJ No 1738 [Bayer]; McKillop v HMTQ (19 August 2011), Toronto CV-10-411911 (Ont Sup Ct) [McKillop]; Sotos LLP, “1291079 Ontario Limited v Sears Canada Inc. Statement of Claim” (5 July 2013) online: http://www.sotosllp.com/wp-content/uploads/2013/07/ Statement-of-claim-Final.pdf [Sears]. 


\section{B. CLASS COUNSEL FEES IN CLASS ACTIONS IN ONTARIO}

To understand class counsel fees in context, we will first describe the development of the modern class action. As a procedural innovation of the English Court of Chancery, ${ }^{3}$ class actions ${ }^{4}$ were originally used (much as they are today) as a device to extend the court's reach to govern the affairs of absent individuals - that is, those who were not immediately before the court and hence not within its obvious jurisdictional ambit. ${ }^{5}$ The rules of practice in Ontario since at least the nineteenth century have permitted class actions, ${ }^{6}$ though the early guidance provided by the rules facilitating such actions was sparse. For example, Rule 75 of the Ontario Rules of Practice, first introduced in 1913 and consisting of a single sentence of thirty words, ${ }^{7}$ remained unchanged and relatively unused for several decades following its introduction. As a simple rule that was drafted in simple terms, there was originally no manifest expression of the specific benefits expected to be realized by Rule 75 . It was not until the Ontario Law Reform Commission took a close and insightful look at class actions in the early 1980s that it became part of the conventional wisdom that class proceedings are beneficial specifically because they

3 For a detailed treatment, see Joseph Story, Commentaries on Equity Jurisprudence, as Administered in England and America, 8th ed. (Boston: Little Brown, 1861); Samuel Stoljar, "The Representative Action: An Equitable Post Mortem" (1956) 3 UWA L Rev 479.

4 We use the terms "class actions," "representative actions," "class proceedings," and "representative proceedings" interchangeably throughout the article.

5 Lord Macnaughton remarked in a 1901 speech at the House of Lords that historically the representative action was "a simple rule resting merely upon convenience." See Duke of Bedford v. Ellis, [1901] AC 1 at 10 (HL).

6 For a lengthy discussion of the history of the class action, see John A Kazanjian, "Class Actions in Canada" (1973) 11 Osgoode Hall LJ 397; and Stephen C Yeazell, From Medieval Group Litigation to the Modern Class Action (New Haven: Yale University Press, 1987). Kazanjian explains that representative proceedings can be traced back to at least the practices of the Courts of Chancery in England in the seventeenth century. The Supreme Court of Canada in General Motors of Canada Ltd v Naken, [1983] 1 SCR 72 [Naken], briefly outlined the history of class actions in Anglo-Canadian law, explaining that procedural rules facilitating representative actions in Ontario (and several other provinces) were based on Order XVI, Rule 9 of the Supreme Court of the United Kingdom. More specifically, in 1881, Rule 98 of the Court of Chancery in Ontario was introduced to facilitate class actions.

7 Rule 75 read: "Where there are numerous persons having the same interest, one or more may sue or be sued or may be authorized by the court to defend on behalf of, or for the benefit of, all." See Naken, ibid. 
can promote (1) judicial economy, (2) access to justice (that is, compensation), and (3) behaviour modification (that is, deterrence). ${ }^{8}$

Following the lead of the United States' amendment of Rule 23 of the Federal Rules of Civil Procedure in 1966, ${ }^{9}$ a move that had dramatically expanded the reach of class proceedings south of the border, the early equitable rules allowing representative proceedings have now yielded to detailed legislation in several Canadian provinces. Quebec acted first in $1978,{ }^{10}$ followed by Ontario in 1992 with the passage of the CPA, and by British Columbia in 1995 with legislation of the same name (and much

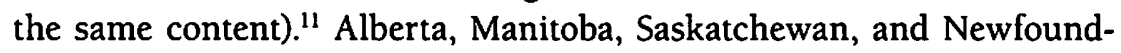
land and Labrador have now also enacted similar legislation enabling class actions. ${ }^{12}$

Ontario's CPA essentially adopted the draft legislation recommended in the 1990 Report of the Attorney General's Advisory Committee on Class Action Reform. ${ }^{13}$ The Ontario legislation was motivated in part by the Supreme Court of Canada's 1983 decision in General Motors of Canada Inc $v$ Naken ${ }^{14}$ In Naken, the Supreme Court held that the simplicity and brevity of Rule 75 rendered it "totally inadequate" to support the "practical problems of all sorts" associated with complex and uncertain class

8 These three ends were identified and described at length in the report of the Ontario Law Reform Commission (OLRC) on class actions: Ontario Law Reform Commission, Report on Class Actions (Toronto: Ministry of the Attorney General, 1982). These ends were approved by the Supreme Court of Canada in Hollick v Toronto (City), [2001] 3 SCR 158, 2001 SCC 68 at para 15. It might be questioned whether class actions are truly consistent with a limited notion of judicial economy to the extent that class proceedings also promote access to justice, since while non-viable claims may be made viable and therefore be brought as class proceedings, they also constitute an additional demand on scarce judicial resources that would not be made if class proceedings were not permitted.

9 See Kenneth W Dam, "Class Actions: Efficiency, Compensation, Deterrence, and Conflict of Interest" (1975) J Legal Stud 47 at 47.

10 An Act Respecting the Class Action, RSQ c R-2.1.

11 Class Proceedings Act, RSBC 1996, c 50.

12 Alberta, Class Proceedings Act, SA 2003, c C-16.5; Manitoba, Class Proceedings Act, CCSM c C130; Newfoundland and Labrador, Class Actions Act, SNL 2001, c C-18.1; and Saskatchewan, Class Actions Act, SS 2001, c C-12.01.

13 Michael G Cochrane et al, Report of the Attorney General's Advisory Committee on Class Action Reform (Toronto: Ontario Ministry of the Attorney General, 1990). The Advisory Committee was formed by then-Attorney General Ian Scott, who had announced at Queen's Park in June 1989 the government's intention to enhance access to class actions in Ontario.

14 Naken, above note 6. 
proceedings. ${ }^{15}$ The Ontario CPA was intended to provide in response an informed (if necessarily imperfect) solution to these practical problems.

How has Ontario's CPA done at providing an informed response to the many practical problems posed by representative proceedings? Unsurprisingly, perfection is elusive. The CPA has not been able to finally solve the issues identified by the Supreme Court of Canada in Naken, though it no doubt represents an improvement over the threadbare Rule 75. Domestic and international experience with class actions demonstrates that numerous difficult issues persist in the day-to-day cut and thrust of class proceedings, even as class actions have grown in prevalence and importance, spurred on by the detailed legislative schemes aimed at making them more manageable and administrable. The remaining difficult issues cannot be easily or tidily reconciled, as is evidenced in part by the extensive academic literature on the subject. ${ }^{16}$

One of the practical problems arising in the context of class actions surrounds the compensation of class counsel. ${ }^{17}$ In a typical lawyer-client relationship, the client undertakes to compensate the lawyer for legal services provided, typically (though not always) on the basis of time spent by the lawyer in providing the services. However, due to the nature of the cases and frequently small claims involved, in class actions, class counsel frequently agree to contingent payment - that is, class counsel undertakes to front the costs of litigation on behalf of the representative plaintiff and the class in exchange for a claim to payment upon settlement or a successful outcome in the courts. However, despite the prima facie similarity with the conventional lawyer-client relationship, class counsel are necessarily more entrepreneurial than are lawyers generally, and exercise a significantly greater degree of control over the litigation.

15 The appeal itself concerned an action which had been purportedly brought on behalf of 4,602 purchasers of 1971 or 1972 Firenzas who at the date of writ had not yet disposed of their vehicles. Justice Estey, for a unanimous Court, held that a more extensive regulation of class actions would be needed to effectively surmount the practical issues. The Court spent much of the judgment discussing the detailed schemes employed by jurisdictions such as Quebec, the State of California, and the Federal Courts in the United States to deal with the many practical problems inherent in representative proceedings.

16 For an excellent introduction to the many conflicts of interest involved in a class action, and a bibliography of the voluminous academic literature the issues have spawned to 1998, see Charles Silver, "Class Actions - Representative Proceedings" in Encyclopedia of Law and Economics (Cheltenham, UK: Edward Elgar, 1999) at 194-240 (Silverl.

17 For a sustained treatment, see Silver, ibid at 211-15. 
This, of course, raises the central problem with representative proceedings: there is no party with the incentive (financial or otherwise) and the ability (expertise and information) to ensure that class counsel looks out for the best interests of all the class members. ${ }^{18}$ At its root, the issue is one familiar to economists; it is a typical principal-agent problem, albeit a particularly acute one. The plaintiff class (the principal) relies on class counsel (the agent) to faithfully pursue the action on the class's behalf. However, the interests of class counsel are likely to be only partially coincident with the interests of the class, since class counsel will at best receive part of the value of the settlement, will have incentives to shirk, and will generally not see fit to maximize the net benefits (that is, costs less settlement or judgment) for the plaintiff class. Representative plaintiffs frequently have little incentive to monitor class counsel because of a collective action problem: most of the benefits of monitoring would accrue to class members who did not bear the costs or hassles of it, while all the costs and hassles would be borne by the representative plaintiff. Even if representative plaintiffs could solve this collective action problem and had appropriate financial incentives to monitor, they would be unlikely to have the ability to do so well. Representative plaintiffs are rarely legally trained, have limited ability to observe the effort and quality of the class counsel's decision-making abilities, and are apt to have little insight into how class counsel's performance would compare with comparable services available from other possible class counsel. For obvious reasons, absent class members (that is, those not directly involved as representative plaintiffs) with current claims and, a fortiori, future claimants, are even less well positioned to monitor class counsel.

There is broad agreement that the principal-agent problem at the core of class actions is not well addressed by current fee arrangements. The enhanced lodestar method, which is frequently used in Ontario, bases compensation on time expended and hourly billing rates, with a premium awarded, usually in the form of a multiple of the base fee, for successful outcomes. Problematically, while the enhanced lodestar method does reward results, in determining the appropriate level of compensation it focuses on a crude proxy for effective representation: the

18 It is frequently the case that class members have varying interests, so that looking out for the "best interests of all the class members" is not even possible. For example, present claimants typically have interests that clash with future claimants. See John C Coffee Jr, "Class Wars: The Dilemma of the Mass Tort Class Action" (1995) 95 Colum L Rev 1343 at 1351 [Coffee, "Class Wars"]. 
time invested by class counsel. As a consequence, all else the same, class counsel are inclined to spend too much time on cases. ${ }^{19}$ Additionally, the method encourages settlements that mutually benefit class counsel and defendants - the parties carrying out settlement negotiations - at the expense of representative plaintiffs and other class members who do not have seats at the negotiating table. ${ }^{20}$

\section{DATA COLLECTION \& ANALYSIS}

The process of collecting the fee approval data for this paper began with the twenty-nine cases from an earlier paper in the Canadian Class Action Review. ${ }^{21}$ We used two different techniques to identify additional relevant cases, noting up cases and noting up legislation. We noted up the previously identified cases using a combination of online legal databases (specifically Quicklaw, Westlaw Canada, and CanLII). The purpose of noting up these cases was two-fold. First, we were looking for any potential updates to cases cited in the previous work. A few cases had updated figures regarding fee approval stemming from subsequent proceedings and those were updated accordingly. Second, we were looking for any additional cases that may not have been published at the time of the previous work. The majority of the newly added cases were found through this method.

We also noted up the Class Proceedings Act, 1992, ${ }^{22}$ using the abovementioned online legal databases. Specifically, we noted up sections 32 and 33 of the CPA using the available legislation citation tools. This process was meant to identify any cases that did not cite or rely on previous class actions cases in Ontario. In a small number of cases, we could not find any reference to fee approval or the specific amounts approved for fees and excluded such cases from the analysis, as they provided no usable data.

19 See Charles Silver, "Unloading the Lodestar" (1992) 70 Tex L Rev 865 at 867.

20 John C Coffee, Jr, "Understanding the Plaintiff's Attorney: The Implications of Economic Theory for Private Enforcement of Law through Class and Derivative Actions" (1986) 86 Colum L Rev 669 at 678 [Coffee, "Understanding the Plaintiffs Attorney"]; Coffee, "Class Wars," above note 18 at 1453-454. For a general discussion of lawyer-client conflicts in compensation for counsel, see Kevin M Clermont \& John D Currivan, "Improving the Contingent Fee" (1978) 63 Cornell L Rev 529; and Earl Johnson Jr, "Lawyers' Choice: A Theoretical Appraisal of Litigation Investment Decisions" (1980-81) 15 Law \& Soc'y Rev 567.

21 Alarie, above note 1.

22 SO 1992, c $6[C P A]$. 
The specific attributes that we extracted from the identified cases (where the attributes were reported) included the amount of approved fees, the docketed fees, the amount of disbursements, the combined (or "all-in") payment to counsel, the amount of the settlement or ruling, the amount initially sought, the area of law, the type of claim, the judge, and the court. In capturing the monetary value data, we attempted to accurately reflect the actual fees, taxes, disbursements, and settlement values where possible. Where the cases indicated that the value was inclusive of taxes, we directly recorded that value. If a case mentioned that this was in "total" or "all-in," we similarly directly recorded the value. Where the cases indicated that the value presented was exclusive of taxes, we used the rate of the GST or HST at the time of the judgment to come up with an approximate value that was inclusive of taxation. While this is an imperfect assumption, it was consistently applied where the information was not reported. Where a judgment simply gave a value that was inclusive of approved fees, disbursements, and taxes, we recorded that as a "combined" variable. Also, where a judgment provided adequate information regarding approved fees, disbursements, and taxes, a "combined" value was computed.

We also used Quicklaw's Mega News database and other online news sources to pinpoint the amounts initially sought in the actions. The authors searched the various parties in conjunction with the phrase "class action" and browsed through media reports filed when the claim was initially made to assess the amount initially sought.

We created dummy variables for the area of law that the case concerned. We identified the cases as belonging to one of the following categories: securities, health, antitrust, financial, pension, employment, and other. We also created indicator variables (yes $=1$, no $=0$ ) for the stage of the proceeding that the case was at when the fee approval was issued. Fee approval orders were classified as occurring either pre-certification, post-certification, or reaching a trial. For the purposes of this classification, pre-certification includes cases that receive certification approval for the purpose of settlement. Of the 104 observed cases, sixty-four were settled pre-certification, thirty-five were settled post-certification, and five reached a trial.

Other information that we tracked included the judge who wrote the fee approval decision and the court the decision was issued in. A total of twenty-five different judges (removing panels of judges) issued fee approvals in the observed cases, most of which were issued in the Superior 
Court of Justice. We used the judge observations to cluster the standard errors on the regressions to account for variance in individual judges.

Finally, we assigned a quantitative valuation of risk to each of the fee approval instances in the dataset. Our risk assessment scores took on integer values from 1 to 3 and were dependent on the novelty of the claim, the previous cases in the area, and our assessment of the complexity of the class action. These values were then used to create two dummy variables, less risky (value of 1 ) and more risky (value of 3). Of the 104 observations, twenty cases were identified as more risky, sixty-three were identified as being of average risk, and twenty-one cases were identified as less risky.

While compiling the list of observations, there were a number of instances where observations on one or more variables were missing from a case. The data that we collected can be classified as missing at random (MAR) data. This is different from missing completely at random (MCAR) data due to the fact that some of the data may be missing because other data is also unavailable. In our dataset, if disbursements were unavailable or unknown to the court at the time of judgment, it might affect whether the reported data included a "combined" value rather than simply an "approved" value. Out of 624 potential variable values in 104 observations, 192 values were missing $(-30.8 \%)$. However, if the amount initially sought is removed (given the different method of data collection), of the 520 potential values derived from the reported decisions, 132 values were missing $(-25.4 \%)$.

Given the small number of observations, and the spread of missing values across different variables, we decided to use a Multiple Imputation (MI) method in order to impute the missing data points. We performed twenty-five imputations using a multivariate normal regression, imputing values for approved fees, docketed fees, disbursements, combined, settlement value, and amount sought.

After generating the imputations, we calculated average values for each imputed variable in Stata using the rowmean function. We also generated the natural log of the average values. If the observation had a negative average value, we would manually set its value to 0.01 in order to ensure that a natural log could be generated. We made this assumption based on the fact that it is impossible to have a negative value for approved fees, docketed fees, disbursements, and so on, in a fee approval. The imputation resulting in a negative average value could be reflective of situations where the class counsel undertakes a claim that pays out far 
below what was expected or billed. They could forgo being compensated for disbursements, receive a multiplier of less than 1 , and so on.

We performed a series of MI estimate regressions, MI average value regressions, and natural log of the MI average value regressions on our dataset. As mentioned above, we clustered the standard errors for each regression for the judge observations (removing panels of judges). Our full regression results are reported in the Appendix below.

As expected, in predicting what the approved fee will be, the settlement value and amount of docketed fees were consistently the most significant factors. In fact, the riskiness of the claim, the area of law, the type of claim, and the stage of settlement were almost uniformly found to not be statistically significant.

Below are two line graphs with 95 percent confidence intervals regarding the relationship between settlement value and approved fees. The settlement value was chosen because it is consistently the most statistically significant variable in predicting the approved fees. The first graph displays settlement values below $\$ 10$ million, and the second graph displays settlement values below $\$ 50$ million. As expected, the confidence interval widens at higher settlement values.

Chart 1: Approved Fees with Confidence Interval $(<\$ 10,000,000)$

Approved Fees with Confidence Interval

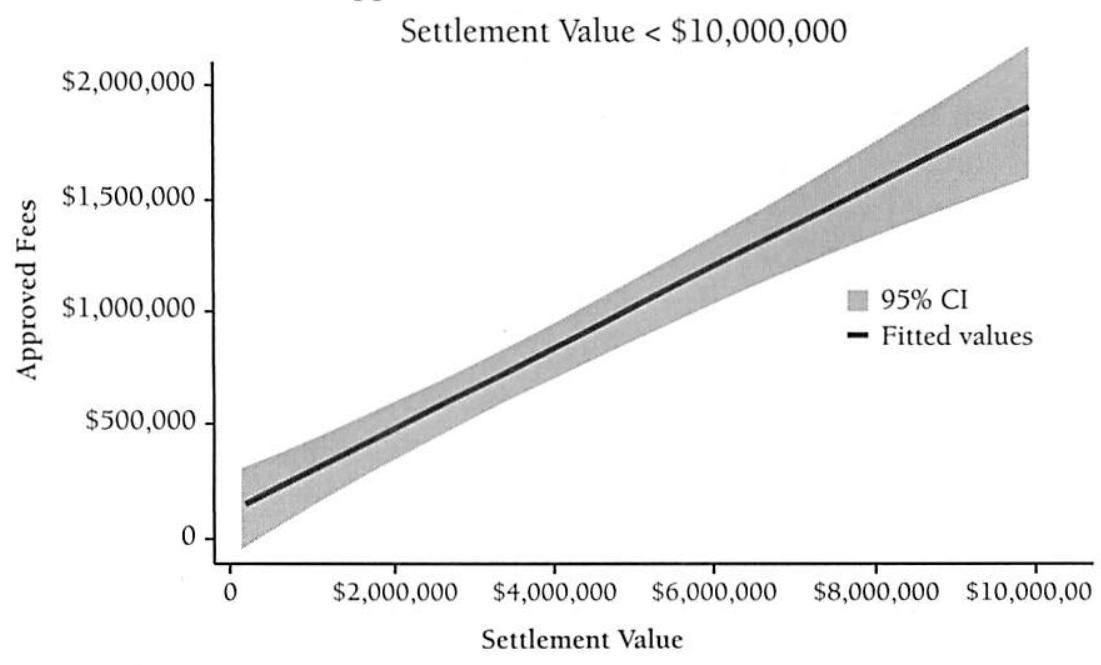


Chart 2: Approved Fees with Confidence Interval $(<\$ 50,000,000)$

Approved Fees with Confidence Interval

Settlement Value $<\$ 50,000,000$

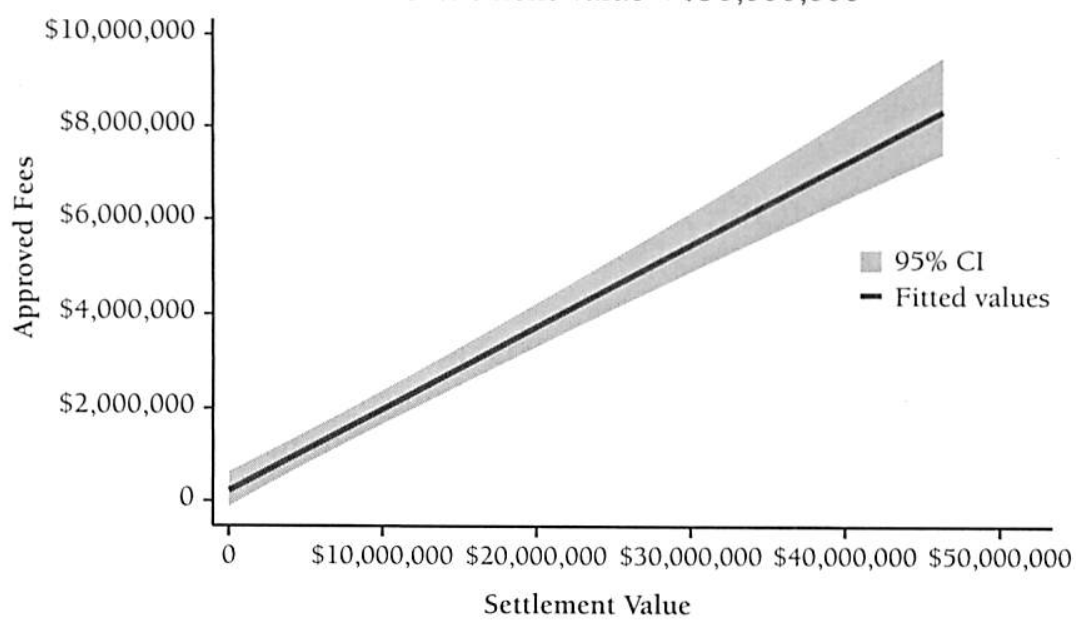

We then generated an interaction variable between settlement amount and docketed fees by multiplying the two variables together (SetDock). Using the natural logs of docketed fees and the interaction term, we were able to predict the expected approved fees for different settlement amount and docketed fees values. An excerpt from the Approved Fee Predicted Value Table is below. The table is reproduced in whole in the Appendix below.

Table 1: Excerpt from Approved Fee Predicted Value Table

\begin{tabular}{|c|c|c|c|c|c|c|}
\hline \multirow[b]{2}{*}{$\begin{array}{c}\text { Docketed } \\
\text { Fees }\end{array}$} & \multicolumn{6}{|c|}{ Settlement Amount } \\
\hline & $\$ 1$ & $\$ 15,0$ & $\$$ & 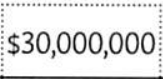 & $\$ 4$ & $\$ 5$ \\
\hline$\$ 200,000$ & & & & & 00 & $\$ 6$, \\
\hline$\$ 300,000$ & $\$$ & $\$ 2$ & $\$ 2,6$ & 00 & 00 & $\$$ \\
\hline$\$ 400,000$ & $\$ 1,465,000$ & $\$ 2,110,000$ & $\$ 2,735,000$ & $\$ 3,945,000$ & $\$ 5,115,000$ & $\$ 6,255,000$ \\
\hline$\$ 50$ & $\$ 1,480,000$ & $\$ 2,135,000$ & $\$ 2,770,000$ & $\$ 3,995,000$ & $\$ 5,180,000$ & $\$ 6,335,000$ \\
\hline$\$ 750,000$ & $\$ 1,515,000$ & $\$ 2,185,000$ & $\$ 2,835,000$ & $\$ 4,090,000$ & $\$ 5,300,000$ & $\$ 6,485,000$ \\
\hline
\end{tabular}

The table provides a rough guide to what class counsel and fee approval judges can expect to be the average approved fee values given the amount of the settlement and the docketed fees submitted.

For the sake of curiosity, we also regressed the natural log of approved fees against dummy variables for the different judges in the dataset as well as the natural logs of settlement value and docketed fees. While none of the coefficients on the judges was statistically significant, Nordheimer J 
claimed the title of the most "reasonable" judge (closest to a coefficient of 0 ), while Lauwer J ranked as the most plaintiff counsel friendly for fee approval. Out of the group of twenty-five, Pollak J was both the most significant (but with a "p-value" of only 0.388 ) and the least plaintiff friendly. One implication of this is that Ontario judges have so far been reasonably consistent in their approach to approving fees for class counsel.

\section{ILLUSTRATION: APPLICATION TO CURRENT CLASS ACTIONS}

An important application of this work is that it can act as a tool for class counsel to support the value of the fees claimed when making submissions on fee approval as well as for the judiciary to use when assessing the reasonableness of a fee approval claim.

To demonstrate the potential efficacy of this analysis, we selected (at the time of writing) five ongoing class actions in Ontario and analyzed them using the dataset of existing cases that we had put together. The five ongoing cases are: Manulife, Pfizer, Bayer, McKillop, and Sears.

The Manulife class action is a securities claim against Manulife Financial and was certified on 25 July $2013 .{ }^{23}$ The class alleges that during the financial crisis of 2008, Manulife failed to disclose the extent of the company's exposure to equity markets. Alleging that this constituted a secondary market misrepresentation under the Ontario Securities Act, ${ }^{24}$ the claim seeks damages for negligence, unjust enrichment, and negligent misrepresentation.

The Pfizer class action is a health claim concerning the anti-smoking drug Champix produced by Pfizer Canada. The class alleges that certain side effects associated with the drug were not properly disclosed to Canadians, specifically psychiatric side effects including depression, anxiety, and suicidal thoughts. ${ }^{25}$ While the original class action named Pfizer Inc.

23 Drew Hasselbeck, "Judge Certifies Class Action against Manulife Financial" The National Post (25 July 2013) online: Financial Post http://business. financialpost.com/2013/07/25/judge-certifies-class-action-against-manulifefinancial/.

24 Securities Act, RSO 1990, c S-5, s 138.3.

25 Canadian Press, "Class-action Suit against Pfizer Canada over Anti-Smoking Drug Champix to Proceed" The National Post (26 July 2013) online: Financial Post http://business.financialpost.com/2013/07/26/class-action-suit-againstpfizer-canada-over-anti-smoking-drug-champix-to-proceed/. 
as well, the approved certification in June 2012 includes Pfizer Canada as defendant for allegedly breaching a duty to warn. ${ }^{26}$

A similar class action faces Bayer Inc. as a result of the Yasmin birth control pill. The Bayer claim asserts that Bayer Inc. did not adequately disclose certain risks associated with taking the pill, including an increased risk of blood clots, strokes, heart attacks, and other medical conditions. ${ }^{27}$ The class was certified both in negligence and for waiver of tort in April $2013 .{ }^{28}$ A class action in the United States regarding the same birth control pill was settled in March 2013.29

The McKillop claim targets the Government of Ontario and alleges that residents of the Rideau Regional Centre suffered abuse while in the government's care. The Rideau Regional Centre, a government-run residential institution intended for individuals with cognitive and physical disabilities, closed in 2009. ${ }^{30}$ The class action alleges that the government breached both a duty of care and a fiduciary duty to residents of the centre to protect them from physical or mental harm and was initially certified in August 2011. ${ }^{31}$ A similar claim has also brought against the government for the operation of the Huronia Regional Centre. ${ }^{32}$

Finally, the Sears class action concerns owners of Sears Hometown stores alleging that Sears runs the Hometown program in a way that is not economically viable for dealers and disregards franchise protection laws. ${ }^{33}$ The claim alleges breach of contract, negligent misrepresentation, and a number of statutory breaches of various provincial Franchises Acts. ${ }^{34}$ As of writing, we do not believe that this action has been certified in Ontario.

26 Pfizer, above note 2.

27 Carmen Chai, "Ontario Judge Gives Green Light to Yasmin, Yaz Class Action Lawsuit" Global (18 April 2013) online: Global News http://globalnews.ca/ news/492236/ontario-judge-gives-green-light-to-yasmin-yaz-class-actionlawsuit/ [Global].

28 Bayer, above note 2.

29 Global, above note 27.

30 Institutional Survivors, Rideau, online: http://www.institutionalsurvivors.com/ background/rideau/ [Rideau].

31 McKillop, above note 2.

32 Rideau, above note 30.

33 CNW, "Canadian 'Sears Hometown' Store Dealers Launch $\$ 100$ Million Class Action against Sears Canada and Sears, Roebuck" Yahoo! (5 July 2013) online: Yahoo! Finance http://ca.finance.yahoo.com/news/canadian-sears-hometownstore-dealers-194600056.html.

34 Sears, above note 2. 
We began with media articles discussing the cases to determine the amount initially sought. We then created a number of different scenarios for possible settlement values, based on the identified relationship between amount initially sought and settlement value in the observed cases. On average, cases in the observed dataset settled for 12.5 percent of the initial amount sought. By taking the average value, as well as a standard deviation above and below, we created high, medium, and low settlement value scenarios for each of the five cases. Additionally, for each potential settlement value, we assigned a different assessment of risk. This resulted in forty-five scenarios that we then ran through the same imputation model we used in generating our initial results. After running twenty-five imputations, we calculated the average values generated for each of the scenarios. The results are presented in Table 2, below.

As mentioned in Section $C$ above, we assigned our own subjective assessment of the riskiness of a case when compiling our dataset. We were surprised to find that riskier cases were not awarded with higher approved fees. There was no positive correlation between what we perceived to be higher risk cases and the value of approved fees. One possible likely explanation of this result is that our subjective method of assessing the riskiness of a case did not adequately capture the same notion of risk as perceived by members of the judiciary. Another possibility is that judges are anchoring on "average" seeming fees and then adjusting insufficiently to reflect the riskiness of the actions. Another possibility is that riskier cases naturally attract more docketed time than less risky cases and, when they settle, are likely to settle for higher amounts. If this is correct, then cases that are riskier will tend to attract higher fees from the effect of the increased risk on docketed fees and settlement values. Of course, it could also be that our assessment of the riskiness of actions was simply not particularly adept. In future work, a more objective assessment of risk based on a stricter qualitative rubric would perhaps be more useful in incorporating this aspect of the fee approval process. As a result, the projected approved fees in Table 2 do not follow the expected positive correlation between approved fees and risk - however, they still indicate the range of approved fees that might be associated with certain settlement values.

The results in Table 2, along with our Approved Fee Predicted Value table in the Appendix, are intended to provide a rough guide regarding fee approval for both practitioners and members of the judiciary. Class counsel in each case can interpolate between the predicted settlement values and the expected docketed fees to arrive at an approximate ex- 
pected valuation for what they would receive in approved fees if a case is an "average" case.

Table 2: Estimated Approved Fees

\begin{tabular}{|c|c|c|c|c|c|}
\hline \multirow{2}{*}{ Case } & \multirow{2}{*}{$\begin{array}{c}\text { Settlement } \\
\text { Scenario }\end{array}$} & \multirow{2}{*}{$\begin{array}{c}\text { Settlement } \\
\text { Value }\end{array}$} & \multicolumn{3}{|c|}{ Expected Approved Fees } \\
\hline & & & High Risk & Medium Risk & Low Risk \\
\hline \multirow{3}{*}{ Manulife } & High & $\$ 188,800,000$ & $\$ 8,690,000$ & $\$ 8,820,000$ & $\$ 8,655,000$ \\
\hline & Medium & $\$ 100,000,000$ & $\$ 7,010,000$ & $\$ 6,255,000$ & $\$ 3,855,000$ \\
\hline & Low & $\$ 10,400,000$ & $\$ 3,555,000$ & $\$ 3,155,000$ & $\$ 2,380,000$ \\
\hline \multirow{3}{*}{ Pfizer } & High & $\$ 94,400,000$ & $\$ 5,325,000$ & $\$ 4,805,000$ & $\$ 5,215,000$ \\
\hline & Medium & $\$ 50,000,000$ & $\$ 4,600,000$ & $\$ 4,495,000$ & $\$ 3,135,000$ \\
\hline & Low & $\$ 5,200,000$ & $\$ 4,370,000$ & $\$ 1,955,000$ & $\$ 1,275,000$ \\
\hline \multirow{3}{*}{ Bayer } & High & $\$ 236,000,000$ & $\$ 10,655,000$ & $\$ 10,015,000$ & $\$ 10,905,000$ \\
\hline & Medium & $\$ 125,000,000$ & $\$ 8,010,000$ & $\$ 6,745,000$ & $\$ 9,095,000$ \\
\hline & Low & $\$ 13,000,000$ & $\$ 4,115,000$ & $\$ 1,300,000$ & $\$ 3,335,000$ \\
\hline \multirow{3}{*}{ McKillop } & High & $\$ 236,000,000$ & $\$ 12,485,000$ & $\$ 10,095,000$ & $\$ 11,360,000$ \\
\hline & Medium & $\$ 125,000,000$ & $\$ 7,555,000$ & $\$ 6,800,000$ & $\$ 7,640,000$ \\
\hline & Low & $\$ 13,000,000$ & $\$ 4,455,000$ & $\$ 3,130,000$ & $\$ 1,860,000$ \\
\hline \multirow{3}{*}{ Sears } & High & $\$ 23,600,000$ & $\$ 3,260,000$ & $\$ 3,455,000$ & $\$ 2,025,000$ \\
\hline & Medium & $\$ 12,500,000$ & $\$ 2,550,000$ & $\$ 2,600,000$ & $\$ 1,110,000$ \\
\hline & Low & $\$ 1,300,000$ & $\$ 640,000$ & $\$ 1,795,000^{\circ}$ & $\$ 1,605,000^{\circ}$ \\
\hline
\end{tabular}

* These imputations resulted in an approved fee value greater than the settlement value.

For the projected scenarios, the approved fees averaged 20.17 percent of settlement value (compared to 22.05 percent for observed cases) and had an average multiplier of 2.31 (compared to 1.95 for observed cases). The slight discrepancy between both metrics could potentially be explained by a tendency for the imputation model to predict lower docketed fees than what was observed in the dataset (while it may be tempting to point to this as evidence of "fee inflation" in practice, there is no basis for that assumption in the model). A higher docketed fee imputation would result in a higher approved fee and therefore a higher average percentage of settlement value, while at the same time potentially lowering the multiplier.

The model predicts that as settlement value increases, the rate of increase in approved fees decreases. This is also consistent with what has been observed in practice. Judges appear to be more hesitant to award high percentage approved fees in cases where the settlement is large. In our dataset, we analyzed the relationship between settlement value and 
the percentage of the settlement value that the approved fees comprised. For the top quartile, the average approved fees were worth 15.51 percent of the settlement value; for the two middle quartiles, the average was 21.94 percent; and for the bottom quartile, the average was 29.10 percent. Rather than approve the terms of the retainer agreement, judges appear to reduce the amount of fees on the basis that the approved fees would be excessive given the amount of work performed and the risk taken on.

\section{E. RECOMMENDATIONS}

We view reliability in how judges approve plaintiff counsel fees as an ideal development for class proceedings in Ontario as it allows class counsel to have a more accurate understanding of the expected value of a claim and it may avoid appellate-level disputes over fee approval since it provides usable precedents for judges to rely on. In order to move towards greater consistency in fee approvals in class actions, we recommend that judges provide adequate information in every fee approval decision.

We would respectfully suggest that judges consider including the following information in their judgments concerning fee approval:

- The value of the approved fees;

- The value of docketed fees;

- Approved disbursements for compensation; and

- The amount of taxes for each of the above.

Judges should avoid issuing a "combined" value that is "all-inclusive" of approved fees, disbursements, and taxes. In instances where a judge does not have access to complete information regarding the value of taxes or disbursements incurred, the judge should strive to include as much information as is available at the time of the judgment, disaggregated appropriately. Proper reporting of these values will allow judges to place greater reliance on previous decisions and will provide additional support for their decisions in the event that their fee approval decision is appealed.

Additional information that ought to be included in fee approval decisions are the nature of the claim (tort, contract, restitution, and so on), as well the judges' own assessment of the riskiness of the claim. We have observed in many of the recent cases that similar wording was used for assessing the appropriateness of fee approval. Judges ought to explain, in the circumstances of the case, how risky they view the claim to be. While there is a concern regarding hindsight bias, we maintain that it 
is still possible for judges to accurately assess the riskiness of the claim. Judges can rely on the novelty of the claim, the evidentiary burdens, previous decisions, and other such factors in determining the riskiness of the claim. More thorough explanations, rather than simply listing the factors considered, would help reduce uncertainty regarding fee approval in Ontario.

It is our hope that this updated analysis will serve to bolster the goal of increased access to justice in class actions in Ontario. A more consistent and well-informed fee approval process should encourage class counsel to take on additional cases that otherwise could be underserved or unrepresented. When the uncertainty regarding the range of fees that are likely to be approved is reduced, class counsel ought to be more confident about the claims that they are willing to bring forward. We encourage more thorough reporting, which will lead to greater reliability and appropriateness in class action fee approval judgments moving forward. 


\section{APPENDIX: REGRESSION RESULTS}

\section{Estimate Regressions on Imputations}

\begin{tabular}{|c|c|c|c|}
\hline Variable & 1 & 2 & 3 \\
\hline Docketed Fees & $1.47002^{* *}$ & $.949437^{\circ}$ & .8960425 \\
\hline t-stat & 3.00 & 2.21 & 2.08 \\
\hline p-value & 0.007 & 0.040 & 0.051 \\
\hline Settlement Amount & $.0229406^{* *}$ & $.0278831^{\cdots \cdots}$ & $.0286507^{* \cdots *}$ \\
\hline t-stat & 3.02 & 4.51 & 4.69 \\
\hline p-value & 0.008 & 0.000 & 0.000 \\
\hline Disbursements & & $3.449154^{\circ}$ & $3.694846^{*}$ \\
\hline t-stat & & 2.21 & 2.45 \\
\hline p-value & & 0.043 & 0.027 \\
\hline Tort & & & $-1727161^{\circ}$ \\
\hline t-stat & & & -2.26 \\
\hline p-value & & & 0.036 \\
\hline Contract & & & -189593.8 \\
\hline t-stat & & & -0.31 \\
\hline$p$-value & & & 0.759 \\
\hline Restitution & & & 250107.4 \\
\hline $\mathrm{t}$-stat & & & 0.51 \\
\hline$p$-value & & & 0.620 \\
\hline \multicolumn{4}{|l|}{ Less Risky } \\
\hline \multicolumn{4}{|l|}{ t-stat } \\
\hline \multicolumn{4}{|l|}{ p-value } \\
\hline \multicolumn{4}{|l|}{ More Risky } \\
\hline \multicolumn{4}{|l|}{ t-stat } \\
\hline \multicolumn{4}{|l|}{ p-value } \\
\hline \multicolumn{4}{|l|}{ Securities Claim } \\
\hline \multicolumn{4}{|l|}{ t-stat } \\
\hline \multicolumn{4}{|l|}{$p$-value } \\
\hline \multicolumn{4}{|l|}{ Health Claim } \\
\hline \multicolumn{4}{|l|}{ t-stat } \\
\hline \multicolumn{4}{|l|}{$p$-value } \\
\hline \multicolumn{4}{|l|}{ Antitrust Claim } \\
\hline \multicolumn{4}{|l|}{ t-stat } \\
\hline \multicolumn{4}{|l|}{$p$-value } \\
\hline \multicolumn{4}{|l|}{ Financial Claim } \\
\hline \multicolumn{4}{|l|}{ t-stat } \\
\hline p-value & & & \\
\hline
\end{tabular}




\begin{tabular}{|c|c|c|c|}
\hline $769^{\circ} 0$ & & $599^{\circ} 0$ & \\
\hline $0+0^{-}$ & & $t 00$ & \\
\hline \multirow[t]{3}{*}{ 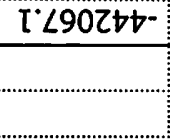 } & & $8 \nabla \varepsilon T \varepsilon t$ & \\
\hline & & $69 \mathrm{~S}^{\circ} 0$ & \\
\hline & & 850 & \\
\hline (pә7)!uo) & & SEOSEIS & \\
\hline $580^{\circ} 0$ & & $\varepsilon 60^{\circ} 0$ & \\
\hline $78^{\circ} \mathrm{I}^{-}$ & & $6 \angle \mathrm{T}-$ & \\
\hline LO9ET8T- & & 8STb89T- & \\
\hline $6 S^{\circ} 0$ & & $887^{\circ} 0$ & \\
\hline 090 & & $\mathrm{~L} \angle{ }^{\circ} \mathrm{O}$ & \\
\hline L8SOTt & & ST982SE & \\
\hline $98 \pi^{\circ} 0$ & & & $t \varepsilon t^{\circ} 0$ \\
\hline$\angle \varepsilon^{\prime} I$ & & & 080 \\
\hline $89 T \angle 0 Z T$ & & & OSEZOIT \\
\hline$\angle S 8^{\circ} 0$ & & & s\&9.0 \\
\hline $80^{\circ} 0^{-}$ & & & $60^{\circ} 0$ \\
\hline $9^{\circ} 0$ TS $\angle 0 \mathrm{~T}^{-}$ & & & $s^{\circ} \diamond Z \angle 892$ \\
\hline \multicolumn{4}{|l|}{$\varepsilon 06^{\circ}$} \\
\hline \multicolumn{4}{|l|}{$20^{\circ} 0^{-}$} \\
\hline \multicolumn{4}{|l|}{ 6S'6EST8- } \\
\hline \multicolumn{4}{|l|}{$586^{\circ} 0$} \\
\hline \multicolumn{4}{|l|}{$200^{\circ}$} \\
\hline \multicolumn{4}{|l|}{$\mathrm{I} \angle 8 \angle \angle O \mathrm{I}^{-}$} \\
\hline \multicolumn{4}{|l|}{$90^{\circ} 0$} \\
\hline \multicolumn{4}{|l|}{$z \angle Z^{\circ}$} \\
\hline \multicolumn{4}{|l|}{.हT0E89T- } \\
\hline $5+0.0$ & $9 \varepsilon 0^{\circ} 0$ & & $\begin{array}{l}280^{\circ} 0 \\
\end{array}$ \\
\hline $0 Z Z$ & Iद' & & $98^{\circ} \mathrm{I}$ \\
\hline 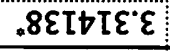 &.$t \varepsilon 9 ح 6 \varepsilon^{\circ} \varepsilon$ & & $2 S+6 S \tau^{\circ} \varepsilon$ \\
\hline $000 \%$ & $000 \%$ & 5000 & 0000 \\
\hline $96 t$ & $\nabla \varepsilon t$ & $\angle Z \varepsilon$ & $\varepsilon t^{\circ}$ \\
\hline$\ldots 8 S Z \angle Z 0^{\circ}$ & ...99ZI8Z0 & $.8 S \varepsilon \angle Z Z 0^{\circ}$ & $\ldots \varepsilon 66 \varepsilon \angle Z 0^{\circ}$ \\
\hline$\tau+0^{\circ} 0$ & $950^{\circ} 0$ & $\varepsilon 00^{\circ}$ & $960^{\circ} 0$ \\
\hline $0 z z$ & $\varepsilon 0 z$ & $\tau \varepsilon \varepsilon$ & $\nabla \tau Z$ \\
\hline. . $\angle \varepsilon 0 t 96^{\circ}$ & $\angle 6 \Rightarrow I \varepsilon \varepsilon \sigma^{\circ}$ & $.09168 t I$ & $.8 \angle t \tau t S 6^{\circ}$ \\
\hline$\angle$ & 9 & $S$ & $t$ \\
\hline
\end{tabular}




\begin{tabular}{|c|c|c|c|}
\hline Variable & 1 & 2 & 3 \\
\hline \multicolumn{4}{|l|}{ Pension Claim } \\
\hline \multicolumn{4}{|l|}{ t-stat } \\
\hline \multicolumn{4}{|l|}{ p-value } \\
\hline \multicolumn{4}{|c|}{ Employment Claim } \\
\hline \multicolumn{4}{|l|}{ t-stat } \\
\hline \multicolumn{4}{|l|}{ p-value } \\
\hline \multicolumn{4}{|l|}{ Other Claim } \\
\hline \multicolumn{4}{|l|}{ t-stat } \\
\hline \multicolumn{4}{|l|}{ p-value } \\
\hline \multicolumn{4}{|l|}{ Cert Settle } \\
\hline \multicolumn{4}{|l|}{ t-stat } \\
\hline \multicolumn{4}{|l|}{ p-value } \\
\hline \multicolumn{4}{|l|}{ After Cert Settle } \\
\hline \multicolumn{4}{|l|}{ t-stat } \\
\hline \multicolumn{4}{|l|}{ p-value } \\
\hline Constant & 68400.62 & 40242.01 & 1368807 \\
\hline t-stat & 0.12 & 0.08 & 1.36 \\
\hline p-value & 0.903 & 0.934 & 0.189 \\
\hline
\end{tabular}




\begin{tabular}{|c|c|c|c|}
\hline 4 & 5 & 6 & 7 \\
\hline & -28277.14 & & -612369.8 \\
\hline & -0.05 & & -0.47 \\
\hline & 0.964 & & 0.643 \\
\hline & (omitted) & & -643998.3 \\
\hline & & & -0.51 \\
\hline & & & 0.616 \\
\hline & 864178.6 & & 557132.3 \\
\hline & 1.38 & & 0.63 \\
\hline & 0.183 & & 0.538 \\
\hline & & -1562299 & 169024 \\
\hline & & -0.81 & 0.10 \\
\hline & & 0.426 & 0.923 \\
\hline & & -2380060 & -460609 \\
\hline & & -1.33 & -0.30 \\
\hline & & 0.196 & 0.764 \\
\hline-173073.1 & -30476.77 & 1830226 & 1546849 \\
\hline-0.37 & -0.44 & 0.89 & 0.68 \\
\hline 0.712 & 0.667 & 0.383 & 0.504 \\
\hline
\end{tabular}


Normal Regressions on Average Imputed Values

\begin{tabular}{|c|c|c|c|}
\hline Variable & 1 & 2 & 3 \\
\hline MI Docketed avg & $1.6659838^{* *}$ & $1.6659838^{* *}$ & 1.3120959 \\
\hline MI Settlement avg & $0.02031412^{*}$ & $0.02031412^{\circ}$ & $0.02303425^{\circ}$ \\
\hline MI Disbursement avg & & $2.3543168^{\circ}$ & $2.6386856^{\circ}$ \\
\hline Tort & & & $-1620114.6^{\circ}$ \\
\hline Contract & & & 28274.086 \\
\hline Restitution & & & 209675.75 \\
\hline \multicolumn{4}{|l|}{ Less Risky } \\
\hline \multicolumn{4}{|l|}{ More Risky } \\
\hline \multicolumn{4}{|l|}{ Securities Claim } \\
\hline \multicolumn{4}{|l|}{ Health Claim } \\
\hline \multicolumn{4}{|l|}{ Antitrust Claim } \\
\hline \multicolumn{4}{|l|}{ Financial Claim } \\
\hline \multicolumn{4}{|l|}{ Pension Claim } \\
\hline \multicolumn{4}{|l|}{ Employment Claim } \\
\hline \multicolumn{4}{|l|}{ Other Claim } \\
\hline \multicolumn{4}{|l|}{ Cert Settle } \\
\hline \multicolumn{4}{|l|}{ After Cert Settle } \\
\hline Constant & -154042.94 & -154042.94 & 967516.23 \\
\hline
\end{tabular}

* $p<0.05$

** $p<0.01$

***** $p<0.001$ 


\begin{tabular}{|c|c|c|c|}
\hline 4 & 5 & 6 & 7 \\
\hline $1.3863518^{\circ}$ & $1.6766515^{*}$ & 1.3743718 & $1.4070254^{\circ}$ \\
\hline $0.02190809^{\circ}$ & $0.02020754^{* *}$ & $0.02227857^{\circ}$ & $0.02138039^{\circ}$ \\
\hline \multirow[t]{4}{*}{$1.9756015^{*}$} & & $2.2699792^{\circ}$ & $2.087335^{\circ}$ \\
\hline & & & $1594525.3^{\circ *}$ \\
\hline & & & 118135.46 \\
\hline & & & -194367.05 \\
\hline 396140.58 & & & -71053.049 \\
\hline \multirow[t]{10}{*}{1074988} & & & 1429635.2 \\
\hline & 239313.92 & & 422750.47 \\
\hline & $-1891544.5^{* *}$ & & $-2004499.9^{\circ}$ \\
\hline & 324885.3 & & (omitted) \\
\hline & 192688.8 & & -476349.2 \\
\hline & -143600.62 & & -276343.28 \\
\hline & (omitted) & & -487925.38 \\
\hline & 615772.43 & & 602450.55 \\
\hline & & -772632.89 & 958378.68 \\
\hline & & -1902561.8 & -16841.166 \\
\hline-457375.54 & -58667.422 & 885119.47 & 503983.18 \\
\hline
\end{tabular}


Normal Regressions on Natural Logs of Average Imputed Variables

\begin{tabular}{|c|c|c|c|}
\hline Variable & 1 & 2 & 3 \\
\hline In MI Docketed avg & .0575103 & .05413189 & .05562597 \\
\hline In MI Settlement avg & $.90284294^{*+\infty}$ & .90097542 & $89838279 * \ldots$ \\
\hline In MI Disbursement avg & & .00665505 & .01381964 \\
\hline Tort & & & -.20568587 \\
\hline Contract & & & .23665554 \\
\hline Restitution & & & .03248626 \\
\hline \multicolumn{4}{|l|}{ Less Risky } \\
\hline \multicolumn{4}{|l|}{ More Risky } \\
\hline \multicolumn{4}{|l|}{ Securities Claim } \\
\hline \multicolumn{4}{|l|}{ Health Claim } \\
\hline \multicolumn{4}{|l|}{ Antitrust Claim } \\
\hline \multicolumn{4}{|l|}{ Financial Claim } \\
\hline \multicolumn{4}{|l|}{ Pension Claim } \\
\hline \multicolumn{4}{|l|}{ Employment Claim } \\
\hline \multicolumn{4}{|l|}{ Other Claim } \\
\hline \multicolumn{4}{|l|}{ Cert Settle } \\
\hline \multicolumn{4}{|l|}{ After Cert Settle } \\
\hline Constant & -1.0980747 & -1.0937309 & -1.0434303 \\
\hline
\end{tabular}

* $p<0.05$

** $p<0.01$

*** $p<0.001$ 


\begin{tabular}{|c|c|c|c|}
\hline 4 & 5 & 6 & 7 \\
\hline .02658754 & .07246091 & .04214514 & .01998353 \\
\hline 8711429 & $.92965719^{\circ * 0}$ & $.89501721^{\circ *}$ & $.91036712^{* * *}$ \\
\hline \multirow[t]{4}{*}{.00968548} & & .00568895 & .03847084 \\
\hline & & & $-.53174258^{\circ}$ \\
\hline & & & .80103943 \\
\hline & & & .75629045 \\
\hline-64986542 & & & -.47888405 \\
\hline \multirow[t]{10}{*}{.04501903} & & & -.14165522 \\
\hline & -14194595 & & -09668534 \\
\hline & -.11017459 & & -.32205952 \\
\hline & .07275752 & & (omitted) \\
\hline & -97303178 & & -2.0298712 \\
\hline & -.51386811 & & $-1.6797717^{\circ}$ \\
\hline & (omitted) & & $-1.0087496^{\circ}$ \\
\hline & .20168615 & & $-.48430312^{\circ}$ \\
\hline & & $-53584718^{\circ *}$ & -.52656496 \\
\hline & & -18216265 & -.03852608 \\
\hline-.16955125 & -1.5227268 & -.44001435 & .15184369 \\
\hline
\end{tabular}




\section{Approved Fee Predicted Value Table}

\begin{tabular}{|c|c|c|c|c|c|c|}
\hline \multirow[b]{2}{*}{$\begin{array}{c}\text { Docketed } \\
\text { Fees }\end{array}$} & \multicolumn{6}{|c|}{ Settlement Amount } \\
\hline & $\$ 1,000,000$ & $\$ 5,000,000$ & $\$ 7,500,000$ & $\$ 10,000,000$ & $\$ 15,000,000$ & $\$ 20,000,000$ \\
\hline$\$ 50,000$ & $\$ 160,000$ & $\$ 695,000$ & $\$ 1,000,000$ & $\$ 1,300,000$ & $\$ 1,870,000$ & $\$ 2,425,000$ \\
\hline$\$ 100,000$ & $\$ 170,000$ & $\$ 720,000$ & $\$ 1,040,000$ & $\$ 1,350,000$ & $\$ 1,950,000$ & $\$ 2,525,000$ \\
\hline$\$ 200,000$ & $\$ 175,000$ & $\$ 750,000$ & $\$ 1,085,000$ & $\$ 1,405,000$ & $\$ 2,025,000$ & $\$ 2,630,000$ \\
\hline$\$ 300,000$ & $\$ 180,000$ & $\$ 770,000$ & $\$ 1,110,000$ & $\$ 1,440,000$ & $\$ 2,075,000$ & $\$ 2,690,000$ \\
\hline$\$ 400,000$ & $\$ 185,000$ & $\$ 780,000$ & $\$ 1,130,000$ & $\$ 1,465,000$ & $\$ 2,110,000$ & $\$ 2,735,000$ \\
\hline$\$ 500,000$ & $\$ 185,000$ & $\$ 790,000$ & $\$ 1,145,000$ & $\$ 1,480,000$ & $\$ 2,135,000$ & $\$ 2,770,000$ \\
\hline$\$ 750,000$ & $\$ 190,000$ & $\$ 810,000$ & $\$ 1,170,000$ & $\$ 1,515,000$ & $\$ 2,185,000$ & $\$ 2,835,000$ \\
\hline$\$ 1,000,000$ & $\$ 195,000$ & $\$ 825,000$ & $\$ 1,190,000$ & $\$ 1,540,000$ & $\$ 2,225,000$ & $\$ 2,885,000$ \\
\hline$\$ 1,250,000$ & $\$ 195,000$ & $\$ 835,000$ & $\$ 1,205,000$ & $\$ 1,560,000$ & $\$ 2,250,000$ & $\$ 2,920,000$ \\
\hline$\$ 1,500,000$ & $\$ 195,000$ & $\$ 845,000$ & $\$ 1,215,000$ & $\$ 1,580,000$ & $\$ 2,275,000$ & $\$ 2,950,000$ \\
\hline$\$ 2,000,000$ & $\$ 200,000$ & $\$ 860,000$ & $\$ 1,240,000$ & $\$ 1,605,000$ & $\$ 2,315,000$ & $\$ 3,000,000$ \\
\hline$\$ 3,000,000$ & $\$ 205,000$ & $\$ 880,000$ & $\$ 1,265,000$ & $\$ 1,645,000$ & $\$ 2,370,000$ & $\$ 3,070,000$ \\
\hline$\$ 5,000,000$ & $\$ 210,000$ & $\$ 905,000$ & $\$ 1,305,000$ & $\$ 1,690,000$ & $\$ 2,440,000$ & $\$ 3,165,000$ \\
\hline
\end{tabular}




\begin{tabular}{|c|c|c|c|c|c|c|}
\hline \multicolumn{7}{|c|}{ Settlement Amount } \\
\hline$\$ 30,000,000$ & $\$ 40,000,000$ & $\$ 50,000,000$ & $\$ 75,000,000$ & $\$ 100,000,000$ & $\$ 250,000,000$ & $\$ 500,000,000$ \\
\hline$\$ 3,5$ & 54 & $\$ 5,5$ & 00 & 000 & $\$ 23$ & 00 \\
\hline$\$ 3,640,000$ & $\$ 4,720,000$ & $\$ 5,775,000$ & $\$ 8,330,000$ & $\$ 10,800,000$ & $\$ 24,700,000$ & $\$ 46,180,000$ \\
\hline$\$ 3,790,000$ & $\$ 4,915,000$ & $\$ 6,010,000$ & $\$ 8,670,000$ & $\$ 11,2$ & $\$ 25,70$ & $\$ 48,060,000$ \\
\hline$\$ 3,880,000$ & $\$ 5,030,000$ & $\$ 6,155,000$ & $\$ 8,875,000$ & $\$ 11,5$ & $\$ 26$ & 000 \\
\hline$\$ 3,945,000$ & $\$ 5,115,000$ & $\$ 6,255,000$ & $\$ 9,020,000$ & $\$ 11,695,000$ & $\$ 26,750,000$ & $\$ 50,015,000$ \\
\hline$\$ 3,995,000$ & $\$ 5,180,000$ & $\$ 6,335,000$ & $\$ 9,135,000$ & $\$ 11,845,000$ & $\$ 27,095,000$ & $\$ 50,660,000$ \\
\hline$\$ 4,090,000$ & $\$ 5,300,000$ & $\$ 6,485,000$ & $\$ 9,355,000$ & $\$ 12,125,000$ & $\$ 27,735,000$ & $\$ 51,855,000$ \\
\hline$\$ 4,155,000$ & $\$ 5,390,000$ & $\$ 6,595,000$ & $\$ 9,5$ & 000 & $\$ 28,195,000$ & $\$ 52,720,000$ \\
\hline$\$ 4,210,000$ & $\$ 5,460,000$ & $\$ 6,680,000$ & $\$ 9,63$ & 000 & $\$ 28,560,000$ & $\$ 53,400,000$ \\
\hline$\$ 4,255,000$ & $\$ 5,520,000$ & $\$ 6,750,000$ & $\$ 9,73$ & $\$ 12,6$ & $\$ 28,860,000$ & $\$ 53,965,000$ \\
\hline$\$ 4,325,000$ & $\$ 5,610,000$ & $\$ 6,860,000$ & $\$ 9,895,000$ & $\$ 12,830,000$ & $\$ 29,345,000$ & $\$ 54,865,000$ \\
\hline$\$ 4,430,000$ & $\$ 5,740,000$ & $\$ 7,025,000$ & $\$ 10,130,000$ & $\$ 13,130,000$ & $\$ 30,035,000$ & $\$ 56,160,000$ \\
\hline$\$ 4,560,000$ & $\$ 5,915,000$ & $\$ 7,235,000$ & $\$ 10,430,000$ & $\$ 13,525,000$ & $\$ 30,930,000$ & $\$ 57,835,000$ \\
\hline
\end{tabular}


Normal Regression on Natural Logs of Average Imputed Variables - Judges

\begin{tabular}{|c|c|c|c|c|}
\hline Variable & Coefficient & $\begin{array}{c}\text { Standard } \\
\text { Error }\end{array}$ & $t$-value & $p$-value \\
\hline In MI Settlement avg & .9383631 & .1364543 & 6.88 & 0.000 \\
\hline In MI Docketed avg & .0394706 & .0758992 & 0.52 & 0.604 \\
\hline Crane & -.5267505 & 1.592711 & -0.33 & 0.742 \\
\hline Cullity & .5018929 & 1.1059 & 0.45 & 0.651 \\
\hline Cumming & .0100062 & 1.088943 & 0.01 & 0.993 \\
\hline Ground & -1.485139 & 2.06391 & -0.72 & 0.474 \\
\hline Haines & $\begin{array}{l}-.6702066 \\
-. .6\end{array}$ & 2.064542 & -0.32 & 0.746 \\
\hline Horkins & .5463748 & 1.167545 & 0.47 & 0.641 \\
\hline Hoy & .4569962 & 1.602716 & 0.29 & 0.776 \\
\hline Lauwers & 1.642222 & 2.096853 & 0.78 & 0.436 \\
\hline Lax & .0886934 & 1.30327 & 0.07 & 0.946 \\
\hline Leitch & .3899887 & 1.408161 & 0.28 & 0.783 \\
\hline Macdonald & .3191675 & 2.06944 & 0.15 & 0.878 \\
\hline Nordheimer & .0061168 & 2.05925 & 0.00 & 0.998 \\
\hline Perell & -.4238837 & .9954727 & -0.43 & 0.671 \\
\hline Pollak & -1.78403 & 2.05696 & -0.87 & 0.388 \\
\hline Rady & .2874857 & 1.595752 & 0.18 & 0.857 \\
\hline Sharpe & .6607881 & 2.064521 & 0.32 & 0.750 \\
\hline Shaughnessy & .4795999 & 2.083567 & 0.23 & 0.819 \\
\hline Strathy & .4389303 & 1.114152 & 0.39 & 0.695 \\
\hline Tausendfreund & .5976545 & 1.595104 & 0.37 & 0.709 \\
\hline vanRensburg & .8636734 & 2.078562 & 0.42 & 0.679 \\
\hline Winkler & -.1996284 & 1.053013 & -0.19 & 0.850 \\
\hline Constant & -1.426337 & 2.193484 & -0.65 & 0.517 \\
\hline
\end{tabular}

